\title{
The Low Velocity Impact Properties of Pandanus Fiber Composites
}

\author{
Hoo Tien Nicholas Kuan ${ }^{1,}$, Meng Chuen Lee ${ }^{2}$, Amir Azam Khan ${ }^{3}$ and Marini Sawawi^ \\ 1. 2. 3. 4 Department of Mechanical and Manufacturing Engineering, Faculty of Engineering, Universiti Malaysia Sarawak, 94300, Kota \\ Samarahan, Sarawak, Malaysia
}

\begin{abstract}
The impact properties of biodegradable Pandanus atrocarpus composite laminate is studied. Laminate samples were fabricated using a hot compression molding technique with high-density polyethylene and extracted Pandanus fiber. Pandanus composites were tested under impact loading in order to study their relative impact performance. Under low velocity impact loading, Pandanus fiber laminates offered an excellent resistance to impact penetration. Tests have shown that increasing the volume fraction of Pandanus fiber can enhance the toughness of the composite. The biodegradable composites imply attractive properties that may be accessible for use in engineering sectors.
\end{abstract}

\section{Introduction}

Environmental concerns are encouraging researchers to seek green and natural solutions to protect and save the planet. The awareness of recycling and green materials usage has increased for the past few years. Life cycle assessment of natural fiber composites has been conducted and these materials have been shown to be ecologically superior to synthetic fiber composites $[1,2]$. One of the solutions to reducing waste is by preventing waste at source during manufacturing. A renaissance in the use of environmentally-friendly composite materials in technical application is taking place in many fields and industries [3]. For instance, the use of natural fiber composites (hemp and sisal) in the European automotive industries (e.g. DaimlerChrysler and BMW) have greatly increased in applications, such as in seat backs, door panels, headliner panels, dashboards, boot lids and rear storage shelves but not in Malaysia automotive industry [4]. Reinforcing green fiber to biodegradable polymer to form composite is likely to provide a beneficial balance between the recognised properties of polymers that are ease in processing and green materials that are biodegradable and abundantly available.

The hydrophilic characteristic of natural fiber is a major disadvantage in reinforcement to composite. Water adsorption in natural fiber composite significantly reduced the mechanical strength and modulus due to the weakening interface of the composite. [5 - 7] Therefore, chemical treatments were introduced to modify the chemical structure of the natural fiber to enhance the adhesion between fiber and matrix. Mercerization is one of the effective treatments on surface modification. The surface roughness of the fiber was increased by destructing the hydroxyl group to form amorphous regions. Suardana et al., Ridzuan et al. and Rokbi et al.

\footnotetext{
a Corresponding author: khtnicholas@unimas.my
}

[8 - 13] explained that the immersion time of the fiber and concentration of sodium hydroxide affects the mechanical properties of the composites. Certain concentration of alkaline treatment and immersion time will improve the mechanical strength. Otherwise, over treatment might damage the strength of the composite.

The mechanical properties of natural fiber composite were determined by the compatibility between the fibermatrix interface and the percentage of fiber volume as reinforcement. The impressive tensile properties of the extracted Pandanus fiber composite have been studied and indicated that reinforced Pandanus fiber improve the tensile strength of the composite [14].

The aim of the research presented here is to study the fiber volume fraction and alkaline treatment on Pandanus fiber composite. Particular attention is given to characterizing the impact response of Pandanus atrocarpus fiber (PAF) reinforced high density polyethylene (HDPE).

\section{Experimental procedures}

\subsection{Composite fabrication}

Pandanus atrocarpus fibers (PAF), or known by the local as "Mengkuang" leaves were extracted and used in this study. Pandanus leaves were obtained near the riverbanks and swampy area in Kuching, Sarawak. PAF were extracted from the leaves with water retting method. The untreated leaves were soaked in distilled water for approximately three weeks before extraction. The extracted fibers were immersed into $1 \%$ concentration of sodium hydroxide $(\mathrm{NaOH})$ for 24 hrs with 1:100, fiber to solution ratio before the fabrication for alkaline treatment study. Pandanus composites were fabricated using hot 